\title{
Evaluation the effects of low-level laser therapy on disc displacement with reduction
}

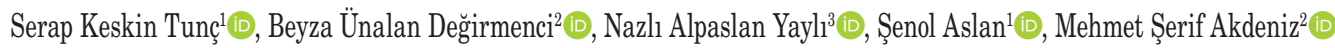 \\ ${ }^{1}$ Department of Oral and Maxillofacial Surgery, Van Yüzüncü Yll University, Faculty of Dentistry, Van, Turkey \\ ${ }^{2}$ Department of Prosthodontic, Van Yüzüncü Yll University, Faculty of Dentistry, Van, Turkey \\ ${ }^{3}$ Department of Periodontology, Van Yüzüncü Yll University, Faculty of Dentistry, Van, Turkey
}

Received: July 10, 2018 Accepted: October 04, 2018 Published online: March 03, 2020

\begin{abstract}
Objectives: This study aims to evaluate the effects of additional low-level laser therapy ( $940 \mathrm{~nm} \mathrm{GaAlAs})$ to the routine occlusal splint therapy on maximal mouth opening (MMO), visual analog scale (VAS) scores, and passive mouth opening (PMO).

Patients and methods: Between January 2016 and March 2018, a total of 40 patients (10 males, 30 females; mean age 22.35 years; range, 18 to 60 years) with disc displacement with reduction of the temporomandibular joint were included. The patients were divided into two groups. Group 1 (control group, $\mathrm{n}=20$ ) received routine non-steroidal anti-inflammatory drug (NSAID) therapy and occlusal splint therapy for eight hours per day for a total of three months. Group 2 (laser group, n=20) received NSAID, occlusal splint therapy and 940 nm wavelength diode laser therapy for two sessions per week for a total of four weeks. The MMO, PMO, and VAS scores were recorded before and at one, two, three, four, and 12 weeks after treatment. The joint and muscle examinations were performed.

Results: A constant decrease was found in the VAS scores in both groups. At four ( $\mathrm{p}=0.008)$ and 12 weeks ( $\mathrm{p}=0.003)$, a statistically significant difference in the VAS scores was observed. At all time points, PMO and MMO scores increased in both groups. The MMO scores were statistically higher in the laser group at all time points $(\mathrm{p}<0.005)$.

Conclusion: Our study results suggest that short-term low-level laser therapy additional to conventional treatment may yield satisfactory outcomes.

Keywords: Low-level laser therapy, occlusal splint, temporomandibular disorders.
\end{abstract}

Temporomandibular disorders (TMDs) are a group of conditions characterized by pain or dysfunction in the temporomandibular joint (TMJ) and related muscles. ${ }^{[1]}$ Symptoms of TMD are muscle and joint pain, limited mandibular movements, mouth opening, and joint sounds during these movements. ${ }^{[2]}$ Although the majority of patients have at least one of these symptoms, only one quarter is aware of these symptoms and 10 to $20 \%$ require treatment. ${ }^{[3]}$

Temporomandibular disorders are mainly classified into three main groups: myofascial pain, joint disc displacement with or without reduction, and degenerative joint disorders. ${ }^{[4]}$ Disc displacement is commonly a non-inflammatory TMJ pathology which may present asymptomatically. ${ }^{[5]}$ Disc displacement with reduction (DDR) is a frequent TMJ disorder. It is typically characterized by a clicking sound during opening and closing of the mouth. ${ }^{[6]}$ Some of the researchers have pointed out that DDR may result from the masticatory muscle contracture. ${ }^{[7]}$ Limitations in mouth opening is also seen in some patients, and the next phases of pain may occur due to secondary muscle spasms, which are related to the soft tissues around the TMJ. ${ }^{[6]}$

Pharmacological treatment of TMD includes analgesics, non-steroid anti-inflammatory drugs (NSAIDs), sedatives, antidepressants, muscle relaxants, vitamins, and antibiotics. In addition, occlusal splints, physical therapy methods such as ultrasound, acupuncture, and laser, and parafunctional habit therapy can be used. ${ }^{[8,9]}$

Corresponding author: Serap Keskin Tunç, MD. Van Yüzüncü Yıl Üniversitesi Diş Hekimliği Fakültesi Ağız Diş Çene Hastalıkları ve Cerrahisi Anabilim Dalı, 65080 Van, Türkiye. e-mail: serapkeskin0165@hotmail.com 
Laser application is the most preferred treatment modality in physiotherapy of TMDs. Low-level laser therapy (LLLT) is a form of phototherapy with its biostimulation and analgesic effects without thermal changes. ${ }^{[10]}$ It is a successful, easy applicable, and short-term treatment option and has become widely used as an alternative treatment for musculoskeletal disorders due to its analgesic, anti-inflammatory, and regenerative effects. ${ }^{[9]}$ Öz et al. ${ }^{[10]}$ and Douglas De Oliveira et al., ${ }^{[11]}$ showed that diode lasers and occlusal splints could be used in the treatment of TMDs.

Many researchers have suggested that occlusal splints are insufficient, although it is the preferred treatment option. ${ }^{[12-15]}$ Some authors ${ }^{[12,16]}$ have proposed that LLLT is a successful treatment modality, while some others have failed to achieve promising results, reporting that LLLT has a placebo effect. ${ }^{[17-19]}$ In the light of literature data, it may be important to combine TMD treatments. ${ }^{[12,14,15]}$ In the present study, we aimed to evaluate the effects of combined occlusal splint and LLLT (940 $\mathrm{nm}$ GaAlAs) on maximal mouth opening (MMO), visual analog scale (VAS), and passive mouth opening (PMO).

\section{PATIENTS AND METHODS}

A total of 286 patients with TMD who were referred to Van Yüzüncü Yıl University, Faculty of Dentistry, Department of Prosthodontics and Maxillofacial Surgery were examined between January 2016 and March 2018. The Research Diagnostic Criteria for
Temporomandibular Disorders (RDC/TMD) were applied with questionnaires to all patients. Inclusion criteria were as follows: having DDR within the past six months; bilaterally TMJ retention; age 18 to 60 years; presence of natural posterior occlusion; and no previous TMD treatment. Exclusion criteria were as follows: having TMD due to psychological reasons; orofacial pain unrelated to TMD; unilaterally TMJ retention; posterior tooth loss; partial removable prostheses; serious orthognathic deformities; systemic diseases; pregnancy or lactation; face or joint infection; and a history of trauma related to TMJ. In total, 40 patients (10 males, 30 females; mean age 22.35 years; range, 18 to 60 years) with DDR of the TMJ were included into the study. The patients were randomly divided into two groups using a randomization procedure (GraphPad Prism version 6; GraphPad Inc., CA, USA). The study flowchart is shown in Figure 1. Inclusion and exclusion criteria are shown in Table 1.

A written informed consent was obtained from each patient. The study protocol was approved by the Van Yüzüncü Yıl University Faculty of Medicine Clinical Research Ethical Committee for this study (YYÜ-06-19072016). The study was conducted in accordance with the principles of the Declaration of Helsinki.

\section{Treatment procedures}

Group 1 (control group, $\mathrm{n}=20$ ) received routine NSAIDs and occlusal splint therapy for eight hours per

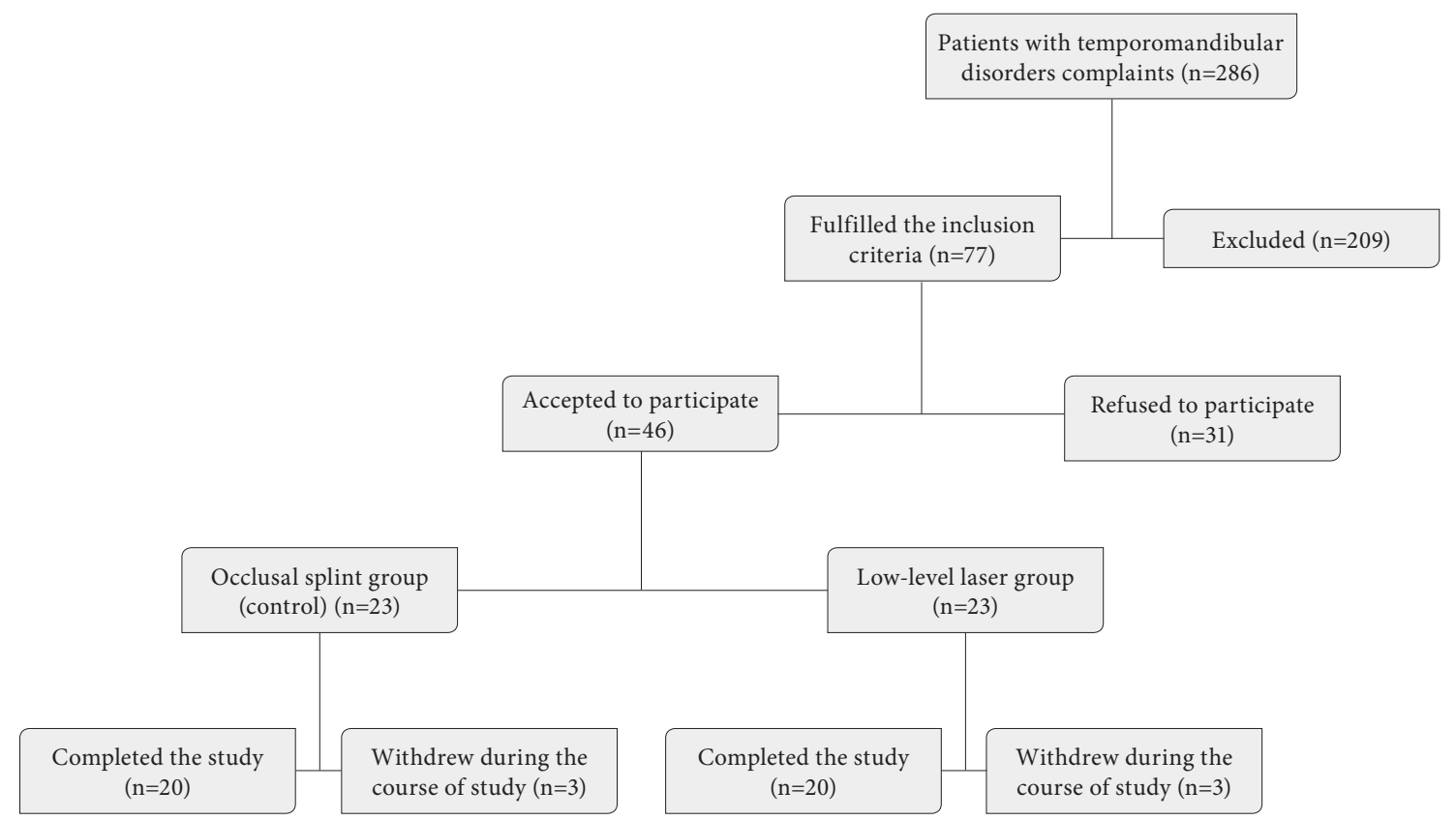

Figure 1. Study flowchart. 


\begin{tabular}{|c|c|c|c|}
\hline \multicolumn{4}{|c|}{$\begin{array}{c}\text { TABLE } 1 \\
\text { Inclusion and exclusion criteria }\end{array}$} \\
\hline \multicolumn{2}{|r|}{ Inclusion criteria } & \multicolumn{2}{|r|}{ Exclusion criteria } \\
\hline$\square$ & Diagnosed with disc displacement with reduction at least 6 months ago & $\square$ & TMD related to psychological reasons \\
\hline$\square$ & Age between 18 and 60 & $\square$ & Orofacial paints except TMD \\
\hline$\square$ & Had natural posterior occlusion & $\square$ & Had posterior teeth loss \\
\hline$\square$ & Did not have any TMD treatment & $\square$ & Partial removable prosthesis \\
\hline \multirow[t]{7}{*}{$\square$} & Bilateral TMJ retention & $\square$ & Serious orthognathic deformities \\
\hline & & $\square$ & Systemic diseases \\
\hline & & $\square$ & Pregnancy \\
\hline & & $\square$ & Nursing history \\
\hline & & $\square$ & Infection at face or joint regions \\
\hline & & $\square$ & Trauma history related to TMJ \\
\hline & & $\square$ & Unilateral TMJ retention \\
\hline
\end{tabular}

day for a total of three months. All occlusal splints were created for the maxillary arch and provided an occlusal relationship considered optimal for the patients. When the splints were in place, prosthodontists checked for musculoskeletal stabilization and tooth contact. Using the splints, canine disocclusion of the posterior teeth during eccentric movement was provided. ${ }^{[21]}$

Group 2 (laser group, $\mathrm{n}=20$ ) received NSAIDs, occlusal splint, and diode laser treatment (Ezlase; Biolase Technology, Inc., Irvine, CA, USA). Laser applications were performed in two sessions per week for a total of four weeks. The treatment was performed using a laser at $940 \mathrm{~nm}$ and $0.3 \mathrm{~W}$ and applied with a bleaching hand piece (Figure 2). The laser contacted the skin and energy was transmitted to the TMJ. In each application site, energy was transmitted with

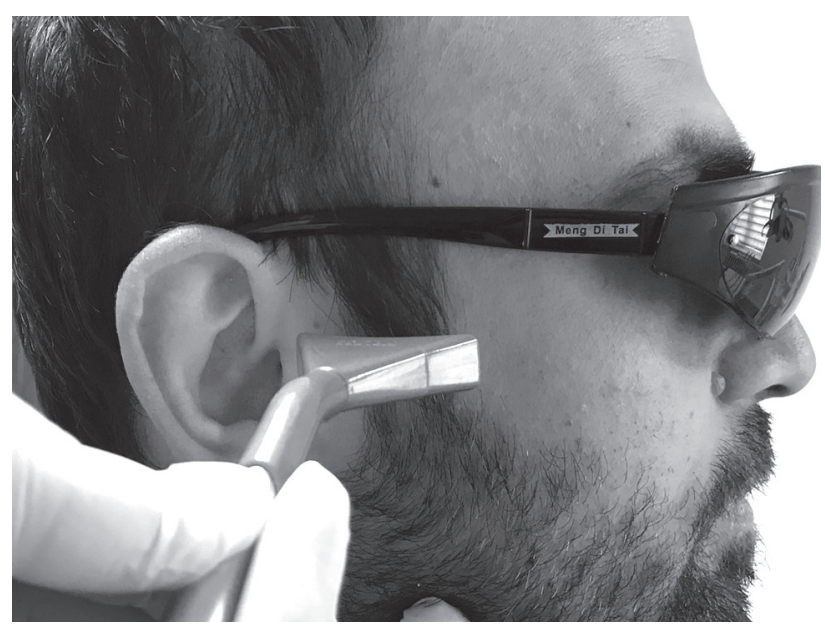

Figure 2. Application of laser to temporomandibular joint. a density of $2.14 \mathrm{~J} / \mathrm{cm}^{2}$ for $20 \mathrm{sec}$ in accordance with the manufacturer's recommendations. The MMO (Figure 3), PMO, VAS scores, muscle, and joint examination data with the RDC/TMD were recorded before and at one, two, three, four, and 12 weeks after treatment.

\section{Statistical analysis}

Power analysis was performed using the $G^{*}$ Power version 3.1.9.2 software (Heinrich-Heine-Universität Düsseldorf, Düsseldorf, Germany). The effect size was calculated as $>0.80$ for the VAS scores for 20 patients per group with a study power of 90 and $95 \%$. For active mouth opening, the effect size was calculated as $>0.80$ with a study power of 87 to $96 \%$. Statistical analysis was performed using the IBM SPSS version 21.0 software

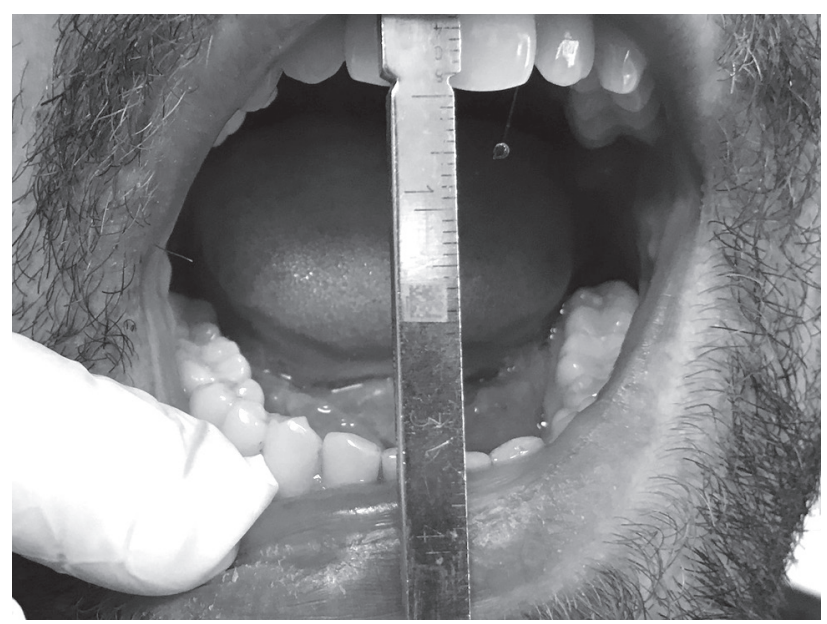

Figure 3. Measurement of maximal mouth opening via a ruler. 


\begin{tabular}{|c|c|c|c|c|c|}
\hline & & $\begin{array}{l}\text { TABLE } \\
\text { Demograph }\end{array}$ & & & \\
\hline & & group & & roup & \\
\hline & $\mathrm{n}$ & Mean \pm SD & $\mathrm{n}$ & Mean \pm SD & $p$ \\
\hline Age (year) & & $23.1 \pm 4.9$ & & $21.3 \pm 4.8$ & 0.248 \\
\hline Sex & & & & & 1 \\
\hline Female & 15 & & 15 & & \\
\hline Male & 5 & & 5 & & \\
\hline
\end{tabular}

(IBM Corp., Armonk, NY, USA). Descriptive statistics were expressed in mean \pm standard deviation (SD), median (min-max), or number and frequency. The Mann-Whitney $U$ test was used to compare the groups, while the Friedman test was used to compare repeated measurements. The Wilcoxon test with the Bonferroni correction was used for multiple comparisons among the repeated data within the same group. A $p$ value of $<0.05$ was considered statistically significant.

\section{RESULTS}

There was no statistically significant difference in sex and age between the groups. Demographic characteristics of the study groups are shown in Table 2.

The VAS scores were recorded at one, two, three, four and 12 weeks in both groups. The VAS scores decreased in both groups over time. However, lower VAS scores were recorded in the laser group at four

\begin{tabular}{|c|c|c|c|c|c|c|c|}
\hline \multirow[b]{3}{*}{ Times } & \multicolumn{6}{|c|}{$\begin{array}{c}\text { TABLE } 3 \\
\text { Comparison of VAS scores between laser and control groups at study time point }\end{array}$} & \multirow{3}{*}{$\frac{\text { Mann-Whitney U test }}{p}$} \\
\hline & \multicolumn{3}{|c|}{ Control group } & \multicolumn{3}{|c|}{ Laser group } & \\
\hline & Mean \pm SD & Median & Min-Max & Mean \pm SD & Median & Min-Max & \\
\hline VAS1 & $5.5 \pm 1.4^{\mathrm{a}}$ & 5 & $3-8$ & $4.5 \pm 1.8^{\mathrm{a}}$ & 4.5 & $1-7$ & 0.076 \\
\hline VAS2 & $5.0 \pm 1.8^{\mathrm{a}}$ & 5 & $2-8$ & $3.8 \pm 2.1^{\mathrm{a}}$ & 3.5 & $1-8$ & 0.060 \\
\hline VAS3 & $4.6 \pm 1.7^{\mathrm{a}}$ & 4.5 & $2-8$ & $3.4 \pm 2.0^{\mathrm{a}, \mathrm{b}}$ & 3 & $0-7$ & 0.056 \\
\hline VAS4 & $4.2 \pm 1.4^{\mathrm{a}, \mathrm{b}}$ & 4 & $2-8$ & $2.5 \pm 2.0^{\mathrm{bc}}$ & 2 & $0-6$ & $0.0080^{\star}$ \\
\hline VAS12 & $3.2 \pm 1.3^{\mathrm{b}}$ & 3.5 & $1-6$ & $1.7 \pm 1.8^{\mathrm{c}}$ & 1 & $0-6$ & $0.0030^{*}$ \\
\hline Friedman $p$ value & & $<0.001$ & & & $<0.001$ & & \\
\hline
\end{tabular}

\begin{tabular}{|c|c|c|c|c|c|c|c|}
\hline \multirow[b]{3}{*}{ Times } & \multicolumn{7}{|c|}{$\begin{array}{l}\text { TABLE } 4 \\
\text { between laser and control groups at study time points }\end{array}$} \\
\hline & \multicolumn{3}{|c|}{ Control group (mm) } & \multicolumn{3}{|c|}{ Laser group (mm) } & \multirow{2}{*}{$\frac{\text { Mann-Whitney } \mathrm{U} \text { test }}{p}$} \\
\hline & Mean \pm SD & Median & Min-Max & Mean \pm SD & Median & Min-Max & \\
\hline Week 1 & $41.9 \pm 9.5^{\mathrm{b}}$ & 45 & $20-56$ & $49.55 \pm 10.1^{\mathrm{b}}$ & 51.5 & $28-65$ & 0.020 \\
\hline Week 2 & $43.2 \pm 8.7^{\mathrm{a}, \mathrm{b}}$ & 46 & $23-57$ & $49.25 \pm 10.7^{\mathrm{b}}$ & 51 & $25-66$ & 0.042 \\
\hline Week 3 & $43.2 \pm 9.7^{\mathrm{a}, \mathrm{b}}$ & 46 & $24-56$ & $48.75 \pm 10.7^{b}$ & 50 & $24-65$ & 0.031 \\
\hline Week 4 & $43.6 \pm 9.6^{\mathrm{a}, \mathrm{b}}$ & 47 & $26-56$ & $50.75 \pm 10.2^{\mathrm{a}}$ & 51.5 & $24-67$ & 0.027 \\
\hline Week 12 & $43.9 \pm 9.4^{\mathrm{a}}$ & 47.5 & $25-56$ & $51.85 \pm 8.7^{\mathrm{a}}$ & 51.5 & $30-67$ & 0.010 \\
\hline Friedman $p$ value & & 0.010 & & & $<0.001$ & & \\
\hline
\end{tabular}




\begin{tabular}{|c|c|c|c|c|c|c|c|}
\hline \multirow[b]{3}{*}{ Times } & \multirow{2}{*}{\multicolumn{6}{|c|}{$\begin{array}{l}\text { TABLE } 5 \\
\text { etween laser and control groups at study time } \\
\text { Laser }(\mathrm{mm})\end{array}$}} & \multirow{3}{*}{$\begin{array}{l}\text { oints } \\
\frac{\text { Mann-Whitney U test }}{p}\end{array}$} \\
\hline & & & & & & & \\
\hline & & \multirow{2}{*}{$\frac{\text { Median }}{41}$} & \multirow{2}{*}{$\frac{\text { Min-Max }}{16-54}$} & \multirow{2}{*}{$\frac{\text { Mean } \pm S D}{37.6 \pm 7.5^{\mathrm{b}}}$} & \multirow{2}{*}{$\frac{\text { Median }}{40}$} & \multirow{2}{*}{$\frac{\text { Min-Max }}{25-50}$} & \\
\hline Week 1 & $37.6 \pm 10.1$ & & & & & & 0.807 \\
\hline Week 2 & $36.7 \pm 12.8$ & 42 & $3-54$ & $37.6 \pm 8.9^{b}$ & 39 & $22-52$ & 0.828 \\
\hline Week 3 & $39.4 \pm 9.6$ & 41.5 & $22-54$ & $38.4 \pm 8.9^{\mathrm{a}, \mathrm{b}}$ & 40.5 & $18-48$ & 0.735 \\
\hline Week 4 & $39.0 \pm 9.3$ & 42 & $22-54$ & $40.0 \pm 8.7^{\mathrm{a}}$ & 42.5 & $18-50$ & 0.704 \\
\hline Week 12 & $39.7 \pm 9.5$ & 42 & $22-54$ & $41.3 \pm 7.3^{\mathrm{a}}$ & 43 & $25-50$ & 0.724 \\
\hline Friedman $p$ value & & 0.058 & & & $<0.001$ & & \\
\hline
\end{tabular}

$(\mathrm{p}<0.008)$ and 12 weeks $(\mathrm{p}<0.003)$, compared to the control group (Table 3).

The MMO and PMO measurements were compared between the groups at the study time points. The MMO scores increased in both groups over time. In addition, there was a statistically significant increase in the MMO scores of the laser group at all time points $(\mathrm{p}<0.005)$ (Table 4).

The PMO measurements were compared between the groups at the study time points. The PMO scores increased in both groups over time and there was no statistically significant difference between the groups (Table 5).

\section{DISCUSSION}

Temporomandibular disorders are characterized by pain and mobility dysfunction in the TMJ area, masticatory muscles, and associated musculoskeletal structures in the head and neck. Typically, TMDs affect females aged between 20 and 40 years. ${ }^{[22]}$ Similarly, in our study, the majority of the patients were females with a mean age of 22.35 years, consistent with previous studies. ${ }^{[15,23-25]}$

The main goal of treatment for TMDs is to control or alleviate symptoms with reversible methods. ${ }^{[26]}$ Clinicians should avoid complicated occlusal therapies and aggressive surgical procedures; therefore, soft diets, hot pack applications, NSAIDs, and occlusal splints are recommended. ${ }^{[27]}$ Treatment with occlusal splints is a reliable option in TMDs to reduce the TMJ load and clinical symptoms. ${ }^{[28]}$ Occlusal splints have no known effect on the clicking sound in patients with DDR, ${ }^{[29]}$ although it is helpful to eliminate interference due to lateral and protrusive movements. ${ }^{[30]}$ In the light of these data, we prescribed
NSAIDs and created splints for the patients, as described by Okeson. ${ }^{[31]}$ Canine-guided full arch maxillary occlusal splints were used for eight hours per day for three months.

Low-level laser therapy is an appealing treatment method with analgesic, anti-inflammatory, biostimulation, and muscle relaxant properties. ${ }^{[16,32,33]}$ However, the mechanism of action has not been fully understood, yet. Some authors have demonstrated that LLLT enhances the pain threshold due to neurostimulation and firing pattern changes, inducing medullar inhibition. ${ }^{[34,35]}$ The penetration and absorption of the laser in the biological tissue is dependent on some variables, the most important of which is the laser wavelength. Different wavelengths $(632,660,810,830890$, and $910 \mathrm{~nm})$ can be used in the treatment of TMDs; ${ }^{[36]}$ however, we were unable to find any study investigating the efficacy of using a laser at $940 \mathrm{~nm}$ in patients with TMDs. Therefore, we examined the effect of laser at $940 \mathrm{~nm}$.

The output power of low-level laser is $<250 \mathrm{~mW}$. These lasers induce photochemical reactions without thermal action on tissue. To create these effects, the force density is a more important criterion than the laser force. If the density is $<670 \mathrm{~mW} / \mathrm{cm}^{2}$, biostimulator effects are created without thermal reactions. ${ }^{[9]}$ In our study, the LLLT at $940 \mathrm{~nm}$ with 6 -W output power and $2.14 \mathrm{~J} / \mathrm{cm}^{2}$ was combined with the conventional occlusal splint therapy. We used these parameters to obtain the biostimulator effects, while avoiding thermal reactions.

In a study by Minakuchi et al. ${ }^{[37]}$ which compared NSAIDs with occlusal splints, a significant healing was reported at four weeks in the splint group, as measured by VAS scores and MMO. In the 
aforementioned study, the authors reported that there were no significant differences between the two groups at eight weeks. In our study, we found a statistically significant difference between the combined laser and occlusal splint groups at four and 12 weeks in terms of the VAS scores and MMO at all time points, consistent with previous studies. ${ }^{[38,39]}$

In their study, Doeuk et al. ${ }^{[39]}$ reviewed the application of LLLT in maxillofacial surgeries and reported that LLLT was not a suitable option, particularly in the treatment of TMDs. Some authors reported satisfactory outcomes with LLLT, ${ }^{[12,16]}$ while some others reported that the effect of LLLT was not different from a placebo. ${ }^{[17-19]}$ Based on these data, we speculate that standard treatment options should be combined with LLLT in the treatment of TMDs. ${ }^{[6,14,23,35]}$

There are some limitations to our study. In LLLT studies, it is helpful to include a placebo group to obtain more objective results. One of the limitations of our study is the lack of a placebo group. Also, initial VAS scores and MMO scores were found to be different between the two groups possibly due to the randomization method of the study groups.

In conclusion, our study results suggest that occlusal splints can alleviate TMD and increase mouth opening to improve daily living activities of patients. Based on these results, we conclude that a combination of LLLT and conventional treatments may have a positive therapeutic effect in the short term. However, further large-scale studies using different laser wavelengths are needed to confirm our study findings.

\section{Declaration of conflicting interests}

The authors declared no conflicts of interest with respect to the authorship and/or publication of this article.

\section{Funding}

The authors received no financial support for the research and/or authorship of this article.

\section{REFERENCES}

1. Wurm MC, Behrends TK, Wüst W, Wiesmüller M, Wilkerling A, Neukam FW, et al. Correlation between pain and MRI findings in TMD patients. J Craniomaxillofac Surg 2018;46:1167-71.

2. Carvalho CM, de Lacerda JA, dos Santos Neto FP, Cangussu MC, Marques AM, Pinheiro AL. Wavelength effect in temporomandibular joint pain: a clinical experience. Lasers Med Sci 2010;25:229-32.

3. Dostalová T, Hlinakova $\mathrm{P}$, Kasparova M, Rehacek A, Vavrickova L, Navrátil L. Effectiveness of physiotherapy and GaAlAs laser in the management of temporomandibular joint disorders. Photomed Laser Surg 2012;30:275-80.
4. Panhoca VH, Lizarelli Rde F, Nunez SC, Pizzo RC, Grecco C, Paolillo FR, et al. Comparative clinical study of light analgesic effect on temporomandibular disorder (TMD) using red and infrared led therapy. Lasers Med Sci 2015;30:815-22.

5. Molinari F, Manicone PF, Raffaelli L, Raffaelli R, Pirronti $\mathrm{T}$, Bonomo L. Temporomandibular joint soft-tissue pathology, I: Disc abnormalities. Semin Ultrasound CT MR 2007;28:192-204.

6. Fayed MM, El-Mangoury NH, El-Bokle DN, Belal AI. Occlusal splint therapy and magnetic resonance imaging. World J Orthod 2004 Summer;5:133-40.

7. Pihut M, Gorecka M, Ceranowicz P, Wieckiewicz M. The Efficiency of Anterior Repositioning Splints in the Management of Pain Related to Temporomandibular Joint Disc Displacement with Reduction. Pain Res Manag 2018;2018:9089286.

8. Alpaslan C, Dolwick MF, Heft MW. Five-year retrospective evaluation of temporomandibular joint arthrocentesis. Int J Oral Maxillofac Surg 2003;32:263-7.

9. Herranz-Aparicio J, Vázquez-Delgado E, ArnabatDomínguez J, España-Tost A, Gay-Escoda C. The use of low level laser therapy in the treatment of temporomandibular joint disorders. Review of the literature. Med Oral Patol Oral Cir Bucal 2013;18:e603-12.

10. Öz S, Gökçen-Röhlig B, Saruhanoglu A, Tuncer EB. Management of myofascial pain: low-level laser therapy versus occlusal splints. J Craniofac Surg 2010;21:1722-8.

11. Douglas De Oliveira DW, Lages FS, Guimarães RC, Pereira TS, Botelho AM, Glória JCR, et al. Do TMJ symptoms improve and last across time after treatment with red $(660 \mathrm{~nm})$ and infrared $(790 \mathrm{~nm})$ low level laser treatment (LLLT)? A survival analysis. Cranio 2017;35:372-8.

12. Pereira TS, Flecha OD, Guimarães RC, de Oliveira D, Botelho AM, Ramos Glória JC, et al. Efficacy of red and infrared lasers in treatment of temporomandibular disorders--a double-blind, randomized, parallel clinical trial. Cranio 2014;32:51-6.

13. Tvrdy P, Heinz P, Zapletalova J, Pink R, Michl P. Effect of combination therapy of arthrocentesis and occlusal splint on nonreducing temporomandibular joint disk displacement. Biomed Pap Med Fac Univ Palacky Olomouc Czech Repub 2015;159:677-80.

14. Murphy GJ. Physical medicine modalities and trigger point injections in the management of temporomandibular disorders and assessing treatment outcome. Oral Surg Oral Med Oral Pathol Oral Radiol Endod 1997;83:118-22.

15. Iwasaki LR, Gonzalez YM, Liu Y, Liu H, Markova M, Gallo LM, et al. Mechanobehavioral Scores in Women with and without TMJ Disc Displacement. J Dent Res 2017;96:895-901.

16. Mazzetto MO, Hotta TH, Pizzo RC. Measurements of jaw movements and TMJ pain intensity in patients treated with GaAlAs laser. Braz Dent J 2010;21:356-60.

17. Emshoff R, Bösch R, Pümpel E, Schöning H, Strobl H. Lowlevel laser therapy for treatment of temporomandibular joint pain: a double-blind and placebo-controlled trial. Oral Surg Oral Med Oral Pathol Oral Radiol Endod 2008;105:452-6 
18. Venezian GC, da Silva MA, Mazzetto RG, Mazzetto MO. Low level laser effects on pain to palpation and electromyographic activity in TMD patients: a doubleblind, randomized, placebo-controlled study. Cranio 2010;28:84-91.

19. Madani AS, Ahrari F, Nasiri F, Abtahi M, Tunér J. Low-level laser therapy for management of TMJ osteoarthritis. Cranio 2014;32:38-44.

20. Dworkin SF, LeResche L. Research diagnostic criteria for temporomandibular disorders: review, criteria, examinations and specifications, critique. J Craniomandib Disord 1992;6:301-55.

21. Celakil T, Muric A, Gökcen Roehlig B, Evlioglu G. Management of pain in TMD patients: Bio-oxidative ozone therapy versus occlusal splints. Cranio 2019;37:85-93.

22. Yap AU, Dworkin SF, Chua EK, List T, Tan KB, Tan $\mathrm{HH}$. Prevalence of temporomandibular disorder subtypes, psychologic distress, and psychosocial dysfunction in Asian patients. J Orofac Pain 2003;17:21-8.

23. Okeson JP, de Kanter RJ. Temporomandibular disorders in the medical practice. J Fam Pract 1996;43:347-56.

24. Yatani H, Sonoyama W, Kuboki T, Matsuka Y, Orsini MG, Yamashita A. The validity of clinical examination for diagnosing anterior disk displacement with reduction. Oral Surg Oral Med Oral Pathol Oral Radiol Endod 1998;85:647-53.

25. Cetiner S, Kahraman SA, Yücetaş S. Evaluation of low-level laser therapy in the treatment of temporomandibular disorders. Photomed Laser Surg 2006;24:637-41.

26. da Silva MA, Botelho AL, Turim CV, da Silva AM. Low level laser therapy as an adjunctive technique in the management of temporomandibular disorders. Cranio 2012;30:264-71.

27. Ferreira LA, de Oliveira RG, Guimarães JP, Carvalho AC, De Paula MV. Laser acupuncture in patients with temporomandibular dysfunction: a randomized controlled trial. Lasers Med Sci 2013;28:1549-58.

28. Koyano K. Temporomandibular disorders. Int J Prosthodont 2009;22:525-6.

29. de Carli ML, Guerra MB, Nunes TB, di Matteo RC, de Luca CE, Aranha AC, et al. Piroxicam and laser phototherapy in the treatment of TMJ arthralgia: a double-blind randomised controlled trial. J Oral Rehabil 2013;40:171-8.

30. Demirkol N, Sari F, Bulbul M, Demirkol M, Simsek I, Usumez A. Effectiveness of occlusal splints and low-level laser therapy on myofascial pain. Lasers Med Sci 2015;30:1007-12.

31. Okeson JP. Management of temporomandibular disorders and occlusion. St. Louis: Mosby; 2003.

32. Chang SW, Chuang CY, Li JR, Lin CY, Chiu CT. Treatment effects of maxillary flat occlusal splints for painful clicking of the temporomandibular joint. Kaohsiung J Med Sci 2010;26:299-307.

33. Xu GZ, Jia J, Jin L, Li JH, Wang ZY, Cao DY. LowLevel Laser Therapy for Temporomandibular Disorders: A Systematic Review with Meta-Analysis. Pain Res Manag 2018;2018:4230583.

34. Bertolucci LE, Grey T. Clinical analysis of mid-laser versus placebo treatment of arthralgic TMJ degenerative joints. Cranio 1995;13:26-9.

35. Hansson TL. Infrared laser in the treatment of craniomandibular disorders, arthrogenous pain. J Prosthet Dent 1989;61:614-7.

36. Rodrigues JH, Marques MM, Biasotto-Gonzalez DA, Moreira MS, Bussadori SK, Mesquita-Ferrari RA, et al. Evaluation of pain, jaw movements, and psychosocial factors in elderly individuals with temporomandibular disorder under laser phototherapy. Lasers Med Sci 2015;30:953-9.

37. Minakuchi H, Kuboki T, Matsuka Y, Maekawa K, Yatani $\mathrm{H}$, Yamashita A. Randomized controlled evaluation of non-surgical treatments for temporomandibular joint anterior disk displacement without reduction. J Dent Res 2001;80:924-8.

38. Shirani AM, Gutknecht N, Taghizadeh M, Mir M. Low-level laser therapy and myofacial pain dysfunction syndrome: a randomized controlled clinical trial. Lasers Med Sci 2009;24:715-20.

39. Doeuk C, Hersant B, Bosc R, Lange F, SidAhmed-Mezi M, Bouhassira J, et al. Current indications for low level laser treatment in maxillofacial surgery: a review. Br J Oral Maxillofac Surg 2015;53:309-15. 